
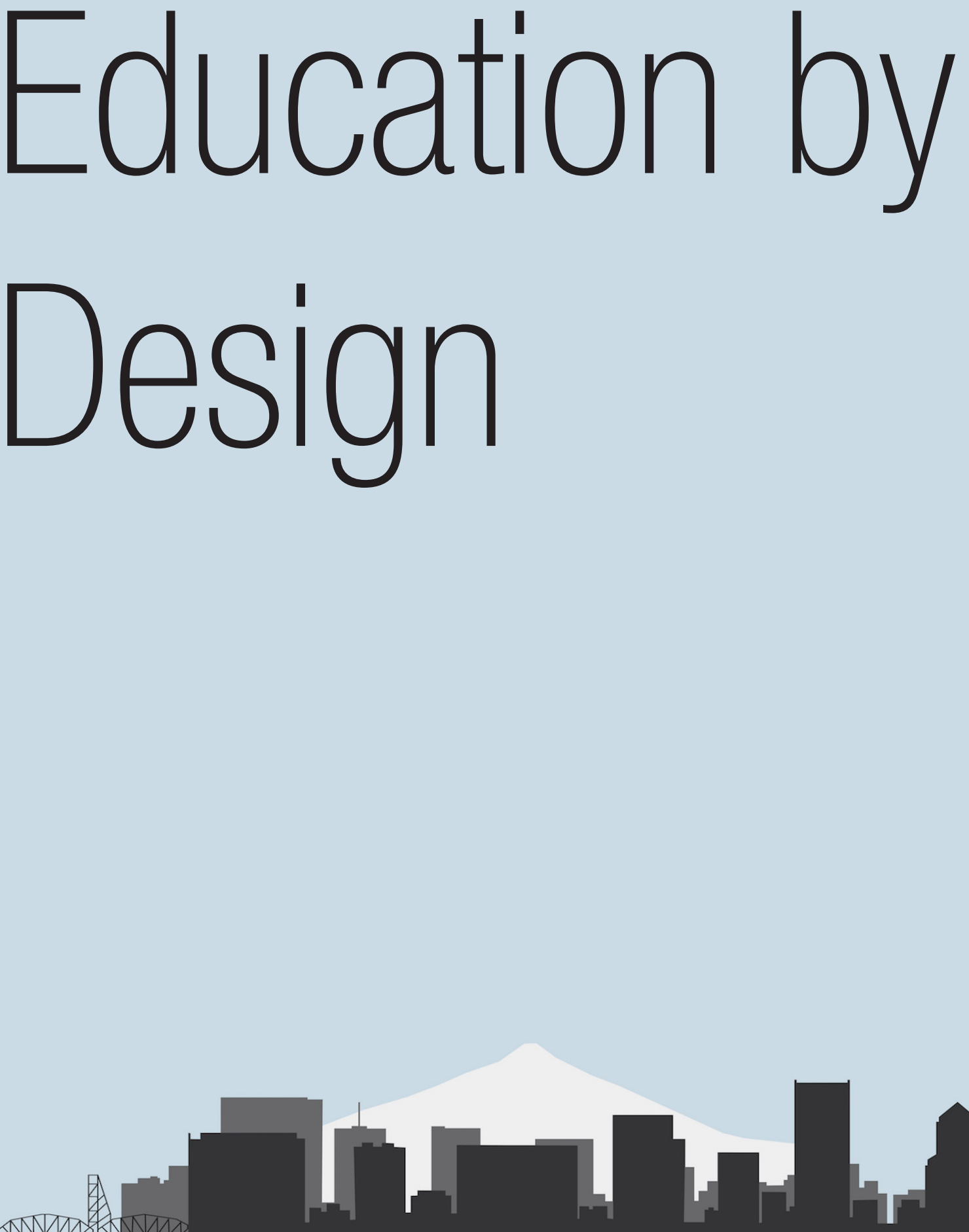

2019 Reynolds Symposium: Education by Design October 18-20, 2019 


\section{Organizing Committee:}

[co-organizers]

Professor Alison Kwok, Ph.D, FAIA, University of Oregon

Emeritus Professor John Reynolds, FAIA, University of Oregon

\section{[Symposium coordinator]}

Isabel Rivera, Ph.D., University of Oregon

Professor Walter Grondzik, P.E., Ball State University

Professor Bruce Haglund, AIA Assoc., University of Idaho

Assistant Professor Emily McGlohn, AIA, Auburn University

Associate Professor Ulrike Passe, lowa State University

Assistant Professor Siobhan Rockcastle, Ph.D., University of Oregon

Sharon Refvem, FAIA, LEED Fellow, Senior Associate and Director, Sustainability Resource Group, Hawley Peterson Snyder 


\title{
Thermodynamic Sunblock: Learning from the 2019 Solar Decathlon Design Challenge
}

\author{
Jonathan Bean, Ph.D. \\ Assistant Professor \\ University of Arizona \\ Tucson, Arizona \\ j.bean@arizona.edu
}

\begin{abstract}
How might architectural education change to accommodate the opportunity of designing thermodynamic systems beyond the building scale? This paper provides an overview of a proposal for a district energy system in Tucson, Arizona originally developed for the 2019 Solar Decathlon Design Challenge. The proposal was developed over the course of one semester with students in two separate classes: a design studio with nine students and an elective with 17 students co-convened during a portion of the scheduled studio time. Teams of students developed three projects: a co-working space (a net exporter of heat), a retrofit school (with a sizable existing chiller system underutilized in summer), and a retrofit of an existing 1950's uninsulated masonry house with the option to add a small additional dwelling unit. The design intention is to use photovoltaic energy generation, air-to-water heat pumps, and an existing network of backyard utility easements to create and move excess thermal energy within a relatively lowdensity superblock in Tucson, Arizona. The long-term goal of the SunBlock project is to make the entire neighborhood net-zero or net-positive while reducing stress on the electric grid.
\end{abstract}

\section{OVERVIEW}

After introducing the SunBlock concept, this paper begins to explore one way architectural education might change in response to the imperative to reduce carbon emissions. Keying the design problem to flows of energy between different building types suggests one potential approach-working across the building and neighborhood scale while considering thermally complementary building types - to studios working on the idea of thermodynamic materialism (Sentkiewicz and Abalos 2015; Moe 2017).

\section{ORIGIN STORIES}

\section{So much sun}

The SunBlock system stemmed from a simple observation: in the desert Southwest there is an abundance of solar energy. Tucson is not hot all year round, but when it is, cooling is a necessity for most buildings. The existing building stock - there were 74,000 single-family homes built in the city between 1940 and 1975, many with no insulation - amplifies the need for cooling, as does the climate crisis, which continues to ratchet up temperatures. While there is an abundance of solar energy and an abundance of housing in the city, there is not an abundance of money. The median house value is $\$ 188,000$, and US census data indicates that one in four Tucsonans lives in poverty. Although electric energy costs are relatively low, at about 12 cents per kilowatt hour, it can be prohibitively expensive for those on a low or fixed income to keep their homes comfortable. While the systemic benefits of increasing energy efficiency are clear, the pathway to achieving this goal is not, especially in cities such as Tucson, where resources are limited, neighborhoods are spread out, and summers will only get hotter.

The underpinnings of the SunBlock system emerged as a response to challenges I faced when designing an energy retrofit of a typical 1950's Tucson house. As part of my academic research program I had completed the Passive House Institute United States Certified Passive House Consultant training, so I used the PHIUS+2015 standard as a target. I quickly realized that without either significantly reducing the amount of north-facing glass or using prohibitively expensive triple-glazed windows that any 
reasonable retrofit strategy would not meet the peak energy limit of $2.8 \mathrm{BTU} / \mathrm{sf}$ for heating or 7.0 BTU/sf for cooling. Instead, I used WUFI energy modeling software to create a dynamic model of interior temperatures, which I evaluated using the principle of passive survivability (Wilson 2018) to determine the optimum level of envelope insulation and began to think about ways to offset the additional energy.

The conventional approach would have been to put a bunch of PV panels on the roof and call it done. A significant public debate in Arizona and the greater Southwest, however, over grid impact fees for residential solar systems, has highlighted the shortsightedness of increasing production without limiting demand. I was also reminded of the aesthetic and urban consequences of turning homes into small-scale power plants when the widening of a nearby arterial included new, mind-bogglingly large power stanchions. Inspired by research on the potential of buildings with significant thermal inertia to function as thermal energy stores (Kensby, Trüschel, and Dalenbäck 2015), I began to investigate the potential of adding on-site thermal storage. Relatively quickly I worked out a schematic design. A modest PV array would provide power to run an air-to-water heat pump. The heat pump would be controlled to operate only when the PV array could provide energy, reducing stress on the grid and eliminating the need to generate source energy for conditioning the house. The heat pump would be sized so that excess energy could be stored in an underground tank. At night, or at other times when the PV array was not generating electricity, the compressor would not need to run, and the only loads needed to provide comfort would be that of a fan in an air handling unit and a pump to move water through a heat exchanger in the storage tank to the coil.

After many Excel spreadsheets and a few headaches-I was trained as a social scientist, not a mechancial engineer!-I had determined the size of the tank, specified an exceptionally efficient Chiltrix air-to-water heat pump, designed the ductwork, and sized the coil. The prototype system is now under construction. When it is completed, I plan to test the efficiency of its operation against my estimates of tank loss and auxiliary energy use.

\section{Ambition}

At the same time construction started on the energy retrofit, I was offered the opportunity to teach a fourth-year option studio where the students would form teams and compete in the Solar Decathlon 2019 Design Challenge. Nine students chose to join the studio, which was taught in conjunction with a separate elective that had an enrollment of 17. I dedicated time at the beginning of the semester to team-building exercises, knowing that since we were short on time our best strategy was to put forward truly innovative ideas. These exercises started with a simple gesture: I took the first class from the design studio to a café, where I led a getting-to-know-you discussion about career paths, their interests outside of architecture, what they wanted to learn in the class, and individual areas of strength. From there, we did a participatory design charette to brainstorm ideas for the project, and ad hoc teams of students formed to research potential sites. Another team building element was that students in the design studio course worked to set rules for how students in the elective course should communicate with them through the Basecamp project management software. While not entirely successful, this did garner better results than my previous attempts to integrate the organization and submission of an overwhelming number of competition deliverables with this project management tool. In general, this aligns with a pedagogical strategy of giving students as much control over the class as possible. I have found that when students choose deadlines and set the penalty for late work, I spend significantly less time checking up, sending reminders, and doing work that feels more like helicopter parenting than university teaching.

One question the organizers of the Reynolds Symposium put forth is "how does the content and pedagogy of a studio shift to integrate issues of climate-related equity, vulnerability, and adaptation in addition to traditional integration of building systems?" One way to do this is to listen to our students. Architecture students, as are most young people today, are gravely alarmed about the climate crisis, though their curriculum to that point in their education had not prepared them to imagine alternative futures. This is not a situation unique to our school; around the globe, accreditation requirements and institutional pressures have made it difficult for design programs to provide students deep knowledge about climate change or the earths' ecosystem, let alone the critical thinking skills needed to shape policy and market systems (O'Rafferty, Curtis, and O'Connor 2014). While the students' attitude toward climate-related equity, vulnerability, and adaptation ranged from fatalistic to wildly optimistic, I found a point of 
common ground on issues of social equity. We spent most of a four-hour studio class in a deep discussion about for whom we should be designing. Our discussion touched on the city's significant population of migrants and refugees, Tucson's status as a sanctuary city, and uncovered the students' earnest desire to make the city a better place.

That discussion also laid bare the students' ambition. They wanted to win the competition. As their instructor, it was my job to support them. At the same time, I had been the faculty lead for another team of students the year before and had first-hand experience of how tough the competition would be, especially because many other universities had significantly more resources dedicated to their teams. Some had sequences of studios linked with support courses; others had multiple faculty members; many had significantly larger teams than ours. I advised that the best way to get one team into the competition would be to pool resources and submit four separate, but related ideas into the first phase of the competition. If we were lucky, one team would become a finalist, and the competition rules would permit us to revise the roster to include the team members now on our unsuccessful submissions. The students agreed, split into four teams targeting the Urban Single Family, Suburban Single Family, Mixed Use, and Elementary School divisions of the competition, and identified potential sites for their projects. We reconvened and collectively decided on a site in central Tucson near the intersection of Grant Road and Alvernon Way, near the geographic center of Tucson. The students submitted their first-round proposals using the Project Progress Report format required by the competition organizers.

The students were thrilled when they received the news that three of our teams had been named as finalists. We had four weeks to complete three full Project Reports. I was equal parts thrilled and terrified. I established a list of goals for our projects:

- Significantly reduce the use of refrigerant with a high global warming potential.

- Reduce stress on the electric grid.

- Respond to the low-density urban conditions that characterize Tucson and other cities in the American west.

- Be applicable to high performance new construction, existing buildings with energy retrofits, and existing historic buildings.

- Conserve water.

- Provide building conditioning congruent with dominant market expectations for comfort and minimal levels of occupant involvement. The system should not rely on devices such as movable shading devices or insulation panels that require regular occupant intervention for performance.

- Improve the economic and social stability of the existing mixed-income neighborhood.

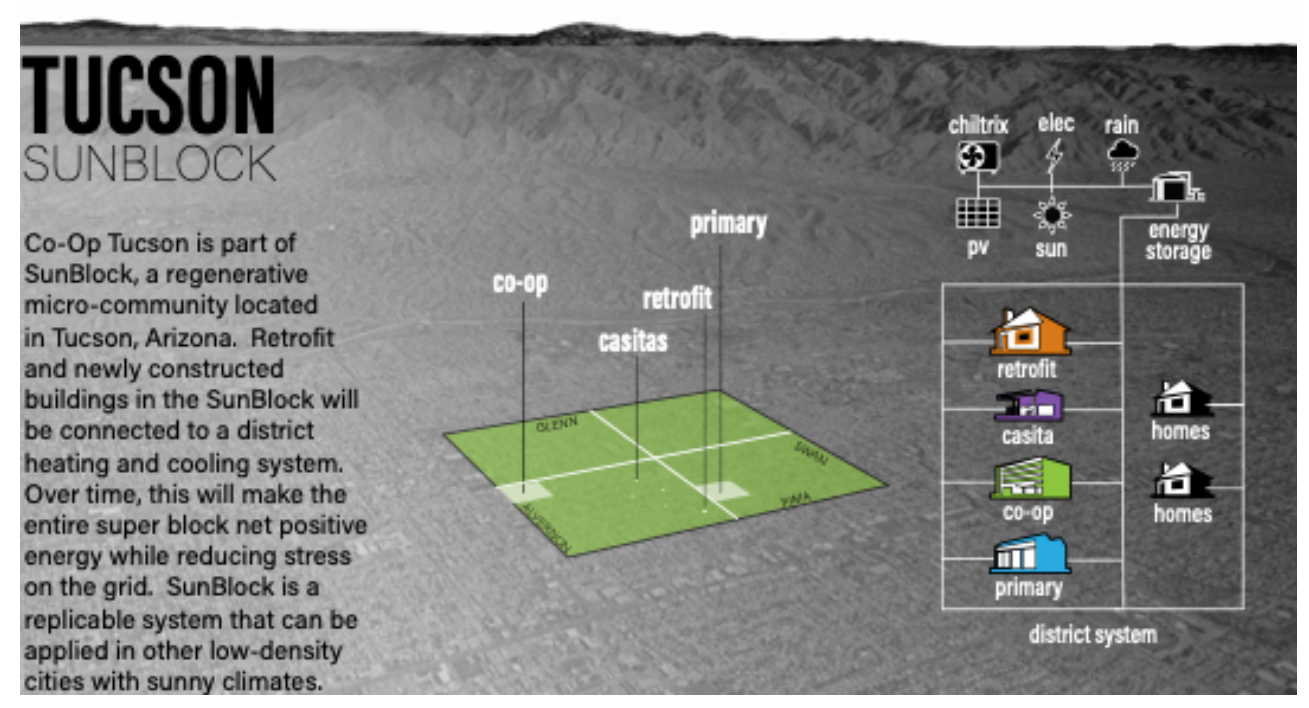

Figure 1. Overview of the SunBlock concept. Source: student work. 


\section{THE SUNBLOCK PROPOSAL}

The three SunBlock proposals link together a retrofit and expanded existing elementary school, a retrofit single-family home, and a big box store retrofit to become a co-working space. Each project used a combination of on-site PV generation, air-to-water heat pump technology, and thermal storage to bank surplus energy. The basic operation of the system is similar between the three projects, though the mechanical equipment and direction of heat flow vary. The student teams worked together to develop an overview graphic shown in Figure 1.

\section{Elementary school}

After interviewing the principal of the elementary school, the students decided that the existing building, a 1950's courtyard design, worked well. They proposed adding a new wing to replace existing modular classrooms, adding continuous insulation, replacing existing single-glazed steel windows with doubleglazed fiberglass units, significantly increasing airtightness, and adding dedicated outdoor air systems ducted in the existing attic spaces. When modeled in WUFI, the improved building exceeded the PHIUS+2018 target. After calculating the required size of the energy storage tank, the students realized the tank could be placed underneath the new addition, a location that would also mitigate some storage losses. As shown in Figure 2, the students proposed turning the tank into an exhibit that would help educate the students and community about the SunBlock concept and provide a space where students could cool off in hot weather. The students had the idea to place the thermal storage tank in the center of the school addition basement enclosed in glass-something like an aquarium. This way, the basement, which would be cool in the summer and warm in the winter, could become a place where students and community members could experience the temperature difference achieved through the SunBlock thermal storage strategy.

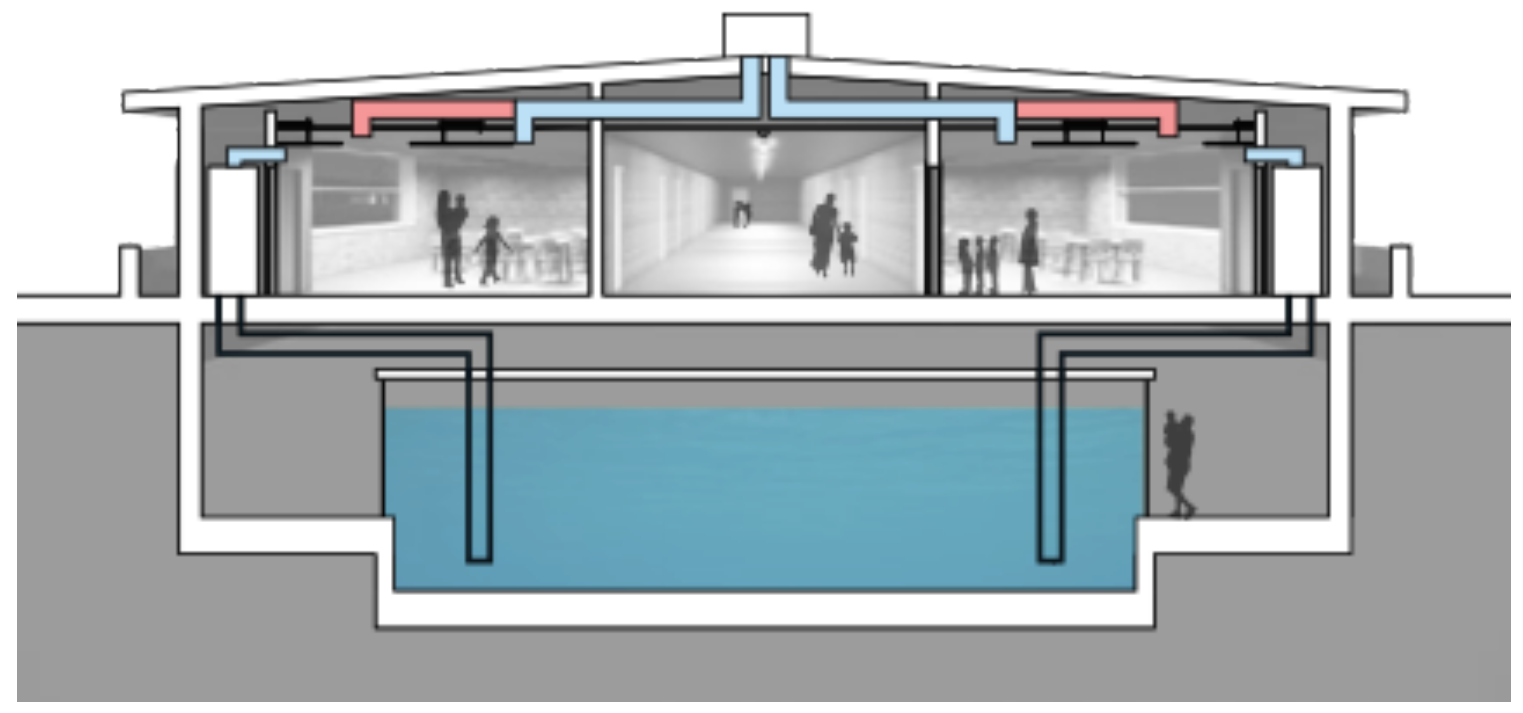

Figure 2. Schematic section of elementary school addition showing storage tank. Source: student work. 


\section{Retrofit single-family home}
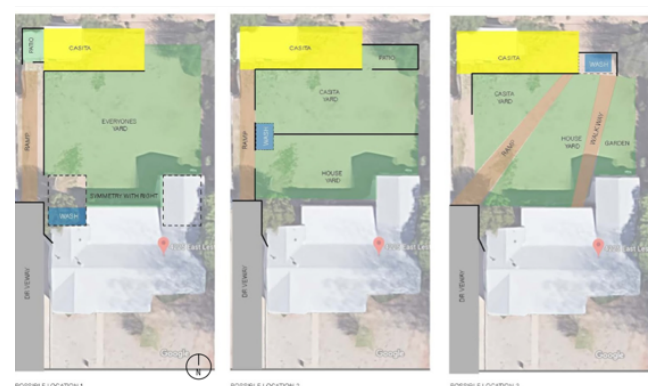

Figure 3. Retrofit house shares mechanical systems with new ADU (casita). Source: student work.

This project used an existing home in Tucson's Garden District neighborhood as a starting point. Faced with the significant cost of adding continuous insulation, new windows, and mechanical systems, the student team realized that they could justify the retrofit cost by adding an additional dwelling unit, typically called a casita in Tucson, in the backyard that could share the mechanical system with the main dwelling. The students began to investigate how the existing yard might be divided between the casita and retrofit house, as shown in Figure 3. Figure 4 shows how this approach can be applied to a majority of the lots in the neighborhood.

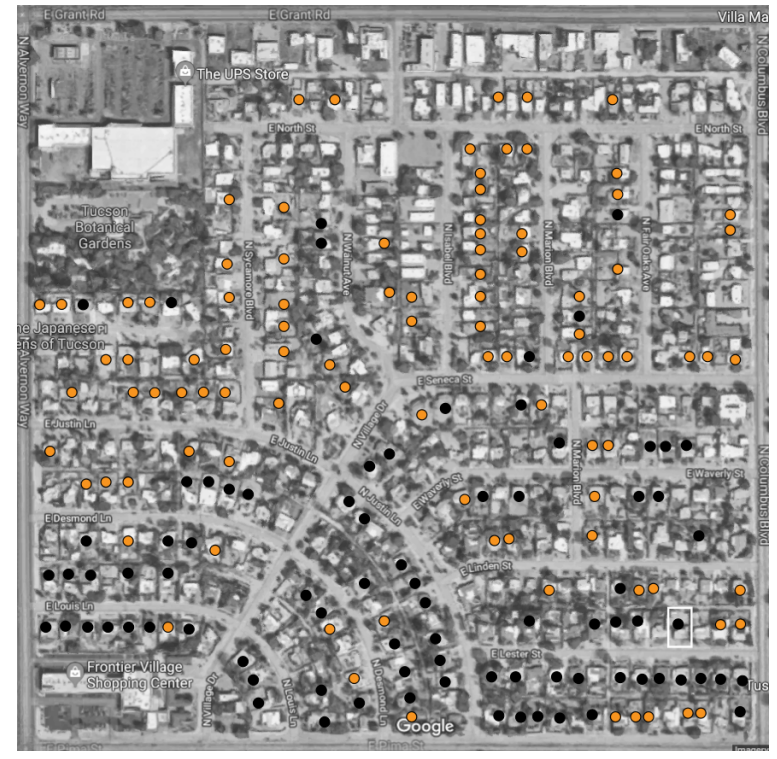

Figure 4. Black dots show potential locations for ADUs (casitas). Source: student work. 


\section{Co-working Space}

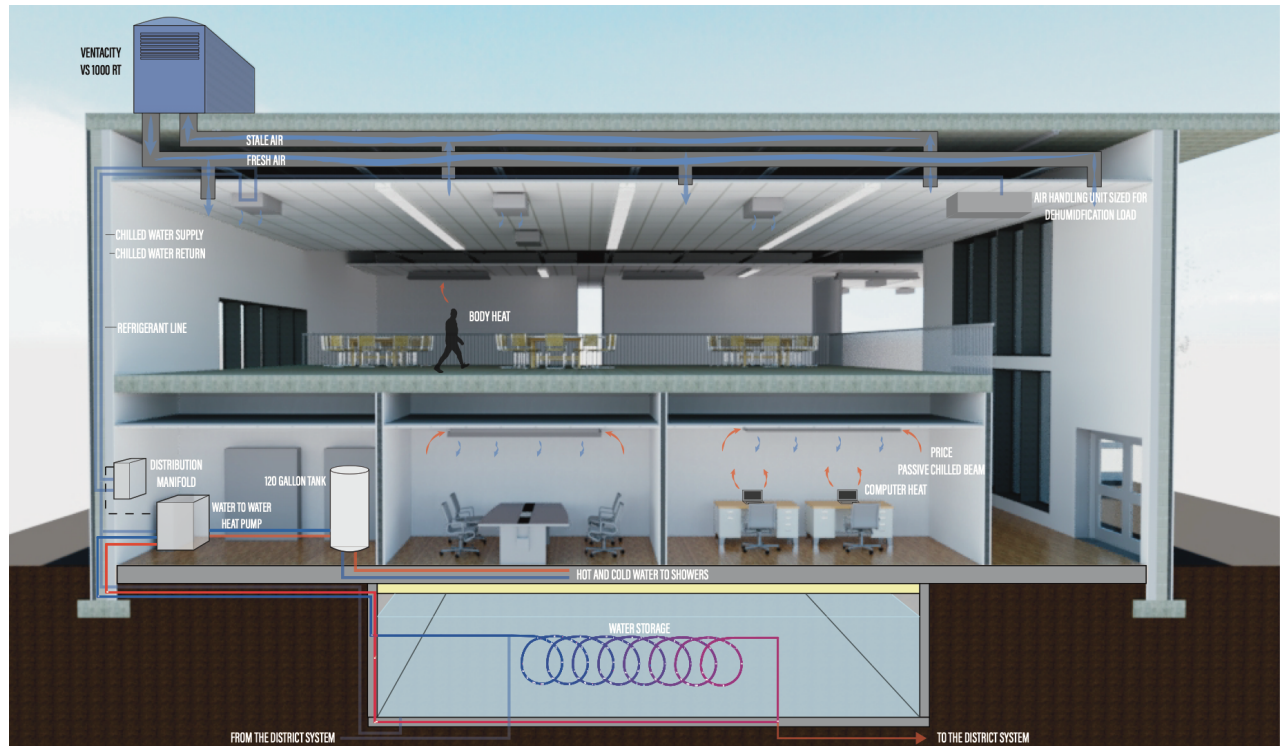

Figure 5. Co-working space with thermal storage. Source: student work.

This project proposed an ambitious program: a co-working space in a former grocery store occupying over 30,000 square feet. The students obtained original plans and found the existing building included a basement space that had been used for refrigeration equipment and storage in the existing building. They proposed repurposing this space for thermal storage. Though building would be a net exporter of heat, this project raised the possibility of a control and distribution system for the different buildings in the SunBlock so that thermal storage could be optimized for distributed and demand-responsive storage of both hot and cold water.

\section{Connecting the SunBlock Projects}

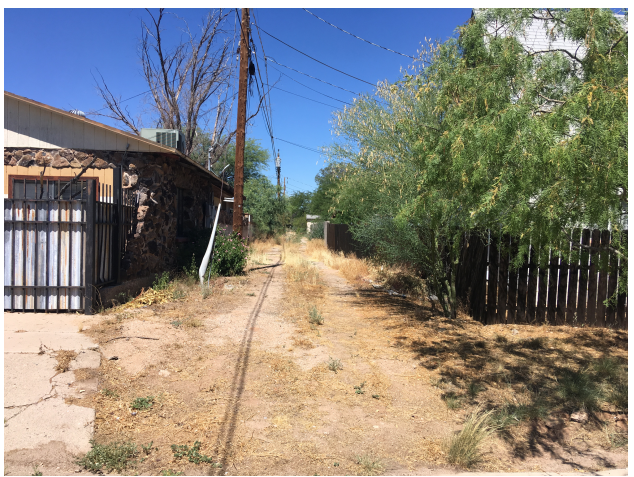

Figure 6. Typical Tucson backyard utility easement. Source: author.

Most residential lots in Tucson include a 5 -foot wide utility easement along the back or one side of the lot. These easements are typically used for overhead power and telecommunications lines and tend to be neglected by property owners (Figure 6). This quirk of Tucson's city grid created an opening for a costeffective way to move energy between the projects while also helping address a lack of pedestrian and bicycle connectivity that is a problem in many midcentury neighborhoods (Figure 7). 


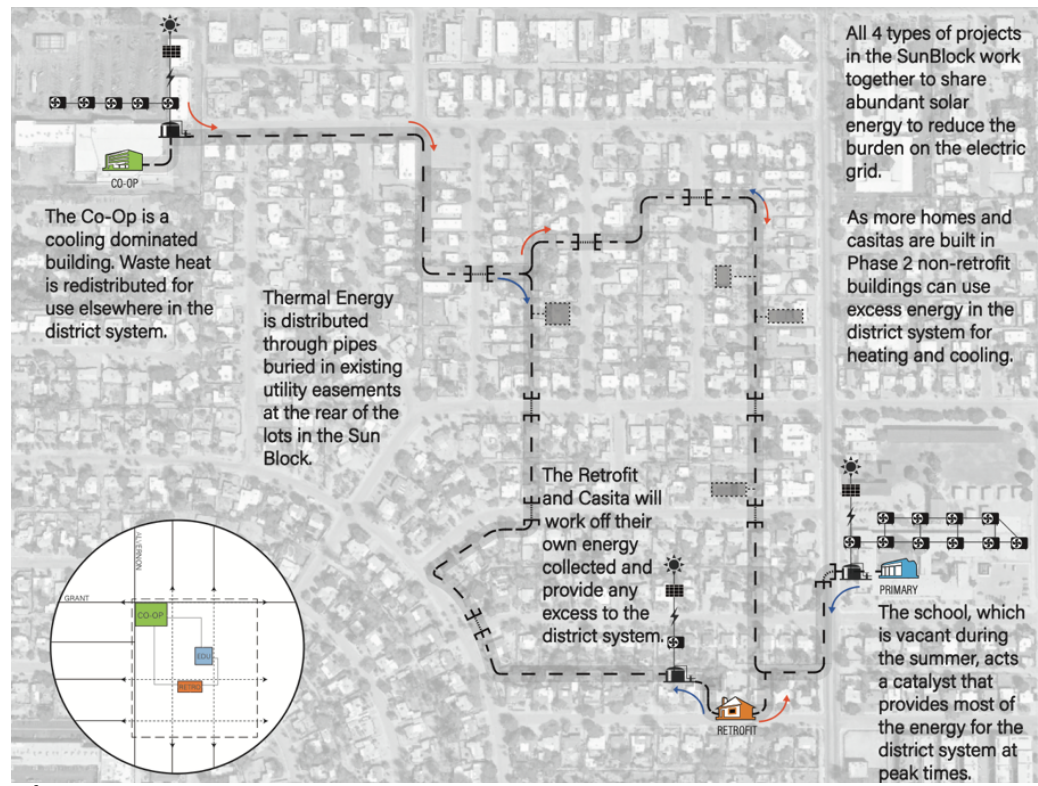

Figure 7. TheSunBlock district loop provides an opportunity to develop bicycle and pedestrian paths in auto-oriented neighborhoods. Source: student work.

\section{Next steps}

I am continuing to develop the SunBlock concept and plan to revisit it in a studio for next year's Solar Decathlon Design Challenge. One area of exploration is how much cooling could be achieved without compressors or refrigerants using the NightSky system (Bourne 2018) or other means of passive cooling (La Roche 2018). Previous research has determined that effective integration of microgrids including thermal storage can increase self-consumption of energy and reduce peak demands (Verda and Colella 2011; Comodi et al. 2015). More development and modeling of the SunBlock system is needed to understand how these effects may work at the scale of a neighborhood. Another question is how the thermal storage tanks, or a series of distributed tanks, might be interconnected to more efficiently extract heat (cf Cruickshank and Harrison 2006) or how other modes of thermal storage (Cruickshank and Baldwin 2016) or how phase-change material (cf Abdelsalam, Lightstone, and Cotton 2019) might be integrated with the SunBlock system.

\section{REFLECTIONS}

\section{“That doesn't work here": on being a weird passive building person in the desert}

It may be helpful to know more about several factors that have influenced how I have guided the development of the SunBlock concept. My thinking about how to teach high-performance building has shifted three times in the past two years. These three shifts in my thinking influenced the way I presented lectures and background information to the students. One key resource was a short video on the subject of systems thinking (Autodesk Academy 2015). It makes the point that the best way to increase the efficiency of a clothes dryer is to increase the effectiveness of the washing machine's spin cycle. ${ }^{1}$ I also used a video explaining Stockholm's district energy system (Fortum 2017), and developed variations of Gail Brager's refrigeration cycle dance to help students gain an embodied understanding of thermodynamics.

The first shift in my thinking occurred when I moved to from central Pennsylvania to Tucson for a job at the University of Arizona. I had started an immersive study of the passive house movement in the United States a few years before, and along the way I became a Certified Passive House Consultant. It is not uncommon for people anywhere to consider their city special or unusual, but in the Sonoran Desert, I was struck by how often this sense of hometown pride translated into a disregard for the strictures of the passive house standard. I have heard visiting critics tell students that insulation is not important because

\footnotetext{
${ }^{1}$ Thanks to Holly Samuelson, who brought this to my attention through the teaching resources section on
} the Society for Building Science Educators website. 
we live in a desert; that thermal bridging isn't worth worrying about; that building airtightness is unnecessary because night flushing could more effectively bring down interior temperatures. (I never heard a satisfactory answer as to how this is possible in July, when the average night ambient temperature is $76^{\circ} \mathrm{F}$.) It was clear that local professionals may be familiar with the German Passivhaus standard, but that they were unaware of the American organization's work to adapt the fair-share principle at the heart of that standard to different climates, including cooling-dominated ones like Tucson's.

Through other experiences I came to understand that in the greater southwest, the combination of cheap energy and climates dominated by cooling, rather than more energy-intensive heating, demand, mean the the already-daunting costs of an energy retrofit may never pencil out. Furthermore, in Tucson, low property values further limit the economic case for energy upgrades that could, if done at scale, significantly reduce the region's contribution to global warming. This is especially unfortunate because despite an ample supply of solar energy, the city relies on a relatively dirty power grid fueled by coalburning power plants.

The second shift in my thinking occurred at the 2018 Living Future Conference. Karina Hershberg and David Mead from PAE presented on the need to pay attention not only to carbon emissions, but also to the global warming potential of buildings. This means carefully considering refrigerant use, reflecting the the finding from the Drawdown project that refrigerant management is the single most important vector to reducing the impact of climate change. This is because R410a, long regarded as an improvement, has a global warming potential more than 2,00o times greater than carbon dioxide, and while less damaging options are coming to market, there does not appear to be a viable option for cooling-dominated climates that is not toxic or flammable. The presenters shared anecdotal evidence that the variable refrigerant flow systems favored by many advocates of energy efficient building have an annual leakage rate of 2-3\%, and pointed out that in places where the energy grid provides mostly renewable energy, such as in Seattle, that a catastrophic refrigerant leak could cancel out the effect of years of operational efficiency. The presentation made me think carefully about the focus on carbon emissions that underpins the concept of EUI and many voluntary standards, including those advocating for passive building. It also made me acutely aware of the significant volumes of refrigerant circulating in hot climates such as Tucson's.

The third shift in my thinking happened as the direct result of the October 2018 release of the Intergovernmental Panel on Climate Change Special Report on Global Warming of $1.5^{\circ}$. At the time I was teaching an introductory course to students in our Sustainable Built Environments program, which is an interdisciplinary undergraduate major that attracts deeply passionate students. The course introduces core concepts such as the three pillars of sustainability, environmental racism, and stabilization wedges. I saw a distinct shift when the dire predictions from the report took center stage on just about every news and social media platform. The students expressed a sense of futility-fueled anger that reflected what they saw as a disconnect between their education and the urgency of change. That experience left me more determined than ever to help build students' sense of agency. I did not want my role as a teacher to reinforce, even inadvertently, the idea that young people are powerless in the face of the climate crisis.

\section{Building agency}

One surprise for me was that when I asked students to think about buildings as having agency to share energy with their neighbors, the students' own sense of agency also increased. First, two of the nine students in the studio course became highly motivated to learn how to use the WUFI energy modeling software. They wanted to have a firsthand understanding of how their design decisions would impact the amount of energy the building used so that they could allow more to be shared in the district loop. Other students enthusiastically took on the task of connecting with potential community and industry partners. One student politely listed to a representative from an energy utility explain that the future would be dominated by chemical batteries and solar farms in the desert, which increased her resolve to explain the advantages of the SunBlock system of on-site generation and storage over a utility-controlled system that consumes land and requires conflict minerals. Another student spent a weekend afternoon on the phone with an industry representative sizing and specifying equipment, only to realize at the end of the day that the system she had designed would use hundreds of pounds of refrigerant. She removed it in favor of another company's equipment. We learned when the jurors were announced that one of our jurors would be from the company whose equipment the student had rejected. The student, determined to make the 
most of her audience, made a strong case in her presentation that the company's strategy should move away from refrigerant-intensive systems and towards less refrigerant-intensive hydronic equipment.

\section{CONCLUSION}

\section{On the boundaries of thermodynamic materialism}

If we are to achieving a carbon-neutral future, we think carefully about the boundaries we draw around the profession and the way we present studio projects. In addition to an ever-widening array of consultant specialties, architecture's origin and continuing status as a tool of power and domination means that issues relating to equity are difficult to address in the classroom because they are considered to exist outside the boundaries of the profession. Consider this in contrast to a field such as urban planning, which also makes a claim of authority over the built environment, but that has long foregrounded equity as a core consideration. Another pragmatic problem is the common-sense understanding of the boundaries of the buildings architecture creates. For example, the concept of Energy Use Intensity, or EUI, stops at the boundary of the building. As articulated by the National Institute of Building Sciences for the Department of Energy, a zero-energy building is defined as "an energy-efficient building where, on a source energy basis, the actual annual delivered energy is less than or equal to the on-site renewable exported energy." This makes intuitive sense, but with current technology large buildings, even those built to aggressive voluntary standards such as the Passive House Institute United States PHIUS+2018, outstrip the potential of on-site renewables.

In contrast, advocates of thermodynamic materialism, such as Kiel Moe, view the field's focus on sustainability as limiting a broader understanding of architecture's energetic possibilities by inscribing artificial boundaries around the building. Though those pushing forward this perspective have not used quite this language, the sense one gets is that aiming to make a single building net-zero is a fool's errand because any kind of calculation requires an artificial, and highly subjective, bounding of time and interconnected systems. The materials we build with today, including wood, steel, and concrete, are the results of energy-intensive industrial processes with inescapable carbon impacts. Therefore, say advocates for this perspective, we should focus not on energy, but rather on a concept developed by Howard Odum, emergy, or Energy Memory, a measurement that aims to capture the quality of energy. While the conversations have not necessarily been linked together, a growing quorum is converging on the need for a shift away from a primary focus on reducing the energy impacts of building operation to a broader consideration of lifetime carbon impacts and global warming potential.

Moe's studio project at Harvard's Graduate School of Design (2017) is one example of how to translate the perspective of thermodynamic materialism to an architecture curriculum dominated by aesthetic considerations. His project marries the typical studio focus on formal innovation with the requirement that students' designs transform into two opposing thermodynamic states: one that diffuses energy and one that collects energy. Students must learn and use energy modeling software to assess their designs. As much as I admire the cleverness of how this project inserts, Trojan horse-style, thermodynamics into a formally-driven curriculum an understanding of thermal qualities, it does not suggest a framework for raising questions of climate-related equity, vulnerability, and adaptation. Nor does it offer an obvious way to discuss how traditional, passive, or other building systems might interact with the architecture.

As much as I admire the cleverness of this studio project, there is an element of Moe's broader body of work, in particular his take on sustainability (2007) that gives me pause. His argument for emergy and understanding flows is tied to an implicit criticism that Moore, Gelfand, and Whitsett (2015) characterize in another context as an irreconcilable schism between two different world views. While it is undeniable that rejecting what those authors call a unit-efficiency frame (EUI is a prime example) in favor of a system-efficacy model (such as emergy) could lead to designs that are better suited to reduce carbon emissions, this move effectively ignores the sociocultural and regulatory contexts, such as building codes and energy efficiency programs, that dictate which ideas can enter the realm of possibility. For this reason, I contend that a focus on net-zero building is a reasonable, pragmatic response to climate change and regulatory regimes such as California's Energy Efficiency Strategic Plan, which set a goal for all new residential buildings to be net zero energy by 2020 and all new commercial buildings to be net zero energy 
by 2030. Although that plan sets a goal for $50 \%$ of commercial buildings to be retrofit to net zero energy by 2030, the question of how the performance of existing buildings - commercial and residential - can be retrofit remains open. Because they mediate between the unit-efficiency frame and the system-efficacy model by requiring the explicit consideration of flows of energy, district energy systems such as the SunBlock proposal suggest one way this might be explored in the design studio.

SunBlock also suggests a way that equity can be considered as part of the design prompt. The idea that established conservation strategies can allow new buildings to share energy with existing buildings represents a new way to think about the fair share principle of carbon emissions that has guided the development of passive building standards. Depending on how they are implemented, district energy systems could also allow the development of a new and potentially more equitable economic model that separates building conditioning from other building energy uses. Building conditioning could be provided as a subscription service that bundles the equipment, maintenance, and energy costs of a district system such as SunBlock into one affordable monthly payment. If run by a public or nonprofit organization, or a investor-owned regulated utility, this arrangement could better guarantee the provision of building conditioning to vulnerable individuals or households suffering economic distress.

\section{Toward resolving contradictions}

As has been pointed out before (for example, see Grover, Emmitt, and Copping 2017), we are on the potential dawn of a new golden age for architectural education, as architects are the profession best situated to respond to the potential to reduce the sizable carbon footprint of new and existing buildings. Yet the growing market and regulatory demand for high performance, net zero energy buildings (or better) has collided head-on with the inherent conservatism of the architectural profession, the model of incremental change embedded in our accreditation standards, and the privileging of the aesthetic qualities of architecture over its other aspects. It feels like we are just treading water-or worse. As Marinanela D'Aprile put it this way in a recent column for Common Edge:

Increasingly, the work that architects do is reduced to discrete, easily itemized tasks: put together a door schedule, do a facade study, lay out a bathroom. Of course, these tasks have always been part of the work of architects, even before global capitalism. The difference now, or at least one of them, is that those tasks are divorced from the big-picture work... the siting, massing, orientation - that's all already been decided by the developer. The more broken-down everyone's responsibilities are, the easier it is to put a price tag on them (and to lower the number on that tag).

Our students sense this through checklist-style assignment prompts that are well-intentioned responses to this new reality. Ever-increasing numbers of students also experience this world first-hand by logging significant hours working for low pay in architectural firms at the same time they are in school. The problem is that we have been dealing with energy performance as yet one more independent variable that can be optimized and delivered by an external consultant. Rather than teaching how energy performance is inextricable from the formal, social, and economic aspects of architecture-and here I am firmly aligned with Moe-conceptualizing energy performance out as a separate, divisible task implicitly treats it as separate from other considerations. The way this is handled in curriculum and in practice sends a clear message to our students that making buildings consume less energy involves irreconcilable trade-offs in appearance, utility, and cost. We must equip designers with an entirely different toolkit if they are to have a positive impact on climate adaptation efforts (Dubois et al. 2016).

Architecture is also foundering in the public realm. Buildings, and by implication architects, are becoming the villains of climate change. The headline of a recent article in The Guardian asks plaintively "What's What's Wrong With Modern Buildings? Everything, Starting With How They're Made" (Landberg and Hodges 2019). This logic prevails despite a wealth of examples and institutional knowledge that proves this need not be the case. In my experience at two different institutions of higher education, I have seen the logic that energy efficient buildings are economically futile remove from consideration the mere possibility of a better performing building. In the popular press, reports about the dangers of increasingly hot summer temperatures often make a causal link between the adoption of air conditioning and the carbon emissions that drive climate change. The New York Times regularly publishes articles with headlines such as "How bad is your Air-Conditioner for the planet?" that stop just short of a blame-the- 
victim logic. While the articles usually acknowledge that, despite the trade offs, cooling saves lives, the message that air conditioning is morally questionable hits home for my students. It does not help that the building where they attend studio is a glass box so routinely over-conditioned that several students keep blankets at their desks. Many students also report that they have been shamed for living in a place where the climate requires air conditioning. In studies of neoliberalism, this process of transferring blame for a systems condition to the individual is called responsibilization (Giesler and Veresiu 2014). In the context of architectural education, it is especially problematic because students quickly learn that the impact of any single building matters little, and that, as D'Aprile points out, someone else is likely to make the big decisions. This reinforces the retreat to the comparatively safe realm of aesthetics, further marginalizing the role of building performance. Yet, if we take a step back, it is clear that systemic changes are needed to achieve the reduction of carbon emissions called for by the Intergovernmental Panel on Climate Change's Special Report on Global Warming of $1.5^{\circ} \mathrm{C}$. In short, we need more educators and students to follow the example of John Reynolds and be brave enough to step into the world of politics and policy (Reynolds 1977).

Despite the headwinds, a primary goal of architectural education, and what I feel should be considered a moral imperative, must be to help our students learn how buildings can help mitigate the climate crisis. The BEEnow Built Environment Education initiative, Architecture 2030 Zero Tool, Solar Decathlon, and other programs are working to ensure that architecture students gain the technical skills and knowledge needed. But there remain two missing pieces that are needed to resolve the contradiction between architecture's potential and how the profession has been constrained by capitalism and other neoliberal forces. First, it is past time for architectural education to consider how the boundaries we draw around buildings, through regulations and standards, and in competition briefs and assignments impact students' sense of agency. Second, we must find a way, even in an already crowded and constrained curriculum, to teach students how to engage with public discourse, so that future generations of architects can gain control of the narrative to establish buildings-and perhaps even architects!-as heroes of the climate crisis.

\section{REFERENCES}

Ábalos, Iñaki, and Renata Sentkiewicz. 2015. Essays On Thermodynamics: Architecture and Beauty. Edited by Lluis Ortega. New York: Actar.

Abdelsalam, M. Y., M. F. Lightstone, and J. S. Cotton. 2019. "A Novel Approach for Modelling Thermal Energy Storage with Phase Change Materials and Immersed Coil Heat Exchangers.” International Journal of Heat and Mass Transfer 136 (June): 20-33.

Autodesk Sustainability Workshop. 2015. "Whole Systems Design: Introduction to Life Cycle Thinking." https://www.youtube.com/watch?v=7mC9xaJC2dQ

Bourne, Richard (Dick). 2018. "Actively Stretching Passive: Adventures with Night Roof Spray Cooling." In Activism in Architecture: Bright Dreams of Passive Energy Design, edited by Margot McDonald and Carolina Dayer, 97-105. New York : Routledge.

Comodi, Gabriele, Andrea Giantomassi, Marco Severini, Stefano Squartini, Francesco Ferracuti, Alessandro Fonti, Davide Nardi Cesarini, Matteo Morodo, and Fabio Polonara. 2015. "MultiApartment Residential Microgrid with Electrical and Thermal Storage Devices: Experimental Analysis and Simulation of Energy Management Strategies." Applied Energy 137 (January): 85466.

Cruickshank, C. A., and S. J. Harrison. 2006. "Experimental Analysis of Stratified Multi-Tank Thermal Storage Configurations for Solar Heating Systems.” In Proceedings of the 2006 American Solar Energy Society Conference, Denver, Colorado, USA. 
Cruickshank, Cynthia. 2016. “Sensible Thermal Energy Storage: Diurnal and Seasonal.” In Storing Energy: With Special Reference to Renewable Energy Sources, edited by Trevor Letcher, 291311. Elsevier.

D’Aprile, Marianela. n.d. "Making Architecture 'Relevant' Will Involve Changing the System It Operates In." Common Edge. https://commonedge.org/making-architecture-relevant-will-involvechanging-the-system-it-operates-in/.

Dubois, Catherine, Geneviève Cloutier, Maja Rosenkilde Rynning, Luc Adolphe, and Marion Bonhomme. 2016. "City and Building Designers, and Climate Adaptation." Buildings 6 (3): 28. https://doi.org/10.3390/buildings6030028.

Fortum. 2017. "This Is How Our District Heating Works." https://www.youtube.com/watch?v=MhJVsSkxg7s.

Giesler, Markus, and Ela Veresiu. 2014. "Creating the Responsible Consumer: Moralistic Governance Regimes and Consumer Subjectivity.” Journal of Consumer Research 41 (3): 840-57.

Grover, Robert, Stephen Emmitt, and Dr Alex Copping. 2017. "Critical Sustainability in the Design Studio. Pedagogic Change through Student Engagement and Collaboration." Architecture Connects AAE 2017 Conference Proceedings, 96-105.

Hershberg, Karina, and David Mead. 2018. "Local Greenhouse Gases: A Bold New Approach to Tracking Sustainability." Presentation at the Living Future Conference, Portland, Oregon. https://livingfutureunconference2018.sched.com/event/CAj5/local-greenhouse-gases-a-boldnew-approach-to-tracking-sustainability.

Intergovernmental Panel on Climate Change. 2018. "Global Warming of $1.5^{\circ} \mathrm{C}$. An IPCC Special Report on the Impacts of Global Warming of $1.5^{\circ} \mathrm{C}$ above Pre-Industrial Levels and Related Global Greenhouse Gas Emission Pathways, in the Context of Strengthening the Global Response to the Threat of Climate Change, Sustainable Development, and Efforts to Eradicate Poverty.” https://www.ipcc.ch/sr15/.

Kensby, Johan, Anders Trüschel, and Jan-Olof Dalenbäck. 2015. "Potential of Residential Buildings as Thermal Energy Storage in District Heating Systems - Results from a Pilot Test.” Applied Energy 137 (January): $773-81$.

La Roche, Pablo. 2018. “Passive Cooling Systems in Times of Climate Change.” In Activism in Architecture: Bright Dreams of Passive Energy Design, edited by Margot McDonald and Carolina Dayer, 87-96. New York : Routledge.

Landberg, Reed, and Jeremy Hodges. 2019. "What's Wrong With Modern Buildings? Everything, Starting With How They're Made.” Bloomberg. https://www.bloomberg.com/news/features/2019-0620/what-s-wrong-with-modern-buildings-everything-starting-with-how-they-re-made.

Moe, Kiel. 2007. “Compelling Yet Unreliable Theories of Sustainability.” Journal of Architectural Education 60 (4): 24-30.

. 2017. "Energy and Form in the Aftermath of Sustainability." Journal of Architectural Education 71 (1): 88-93.

O’Rafferty, Simon, Hannah Curtis, and Frank O’Connor. 2014. "Mainstreaming Sustainability in Design Education - a Capacity Building Framework." International Journal of Sustainability in Higher Education 15 (2): 169-87.

Reynolds, John S. 1977. “Something of a Gadfly.” Journal of Architectural Education 30 (3): 58-61. 
Verda, Vittorio, and Francesco Colella. 2011. "Primary Energy Savings through Thermal Storage in District Heating Networks.” Energy 36 (7): 4278-86.

Wilson, Alex. 2018. "Resilience as a Driver of Passive Design." In Activism in Architecture: Bright Dreams of Passive Energy Design, edited by Margot McDonald and Carolina Dayer, 132-39. New York : Routledge. 